\title{
Linguagem e acordos linguísticos em Aristóteles: contribuições para uma educação artística, poética e retórica ${ }^{1}$
}

\author{
Erika Natacha Fernandes de Andrade* \\ Marcus Vinicius da Cunha**
}

Resumo: Filiado ao movimento de revisão da filosofia aristotélica iniciado no século $\mathrm{XX}$, e seguindo uma das linhas de investigação do Grupo de Pesquisa Retórica e Argumentação na Pedagogia (USP/CNPq), este texto aborda as noções de linguagem e acordos linguísticos presentes no discurso de Aristóteles. Ao valorizar o logos como imprescindível à atualização de uma psique apta a conduzir acordos coletivos e elaborar discursos internos virtuosos, Aristóteles situa a educação no âmbito de um universo artístico, poético e retórico. O projeto educacional aristotélico oferece força e poder ao homem, com o intuito de melhorar a sua vivência em coletividade e consolidar a felicidade individual, que é indissociável da construção da polis ideal.

Palavras-chave: Aristóteles. Linguagem. Educação. Arte. Retórica.

\section{Language and linguistic agreements in Aristotle: contributions to an artistic, poetic, and rhetorical education}

Abstract: Affiliated to the movement of revision of the Aristotelian philosophy

1 A pesquisa que originou este trabalho contou com subsídios do CNPq.

* Doutora em Educação pela Universidade Estadual Paulista (UNESP) “Júlio de Mesquita Filho”. Professora do Curso de Pedagogia da Faculdade de Filosofia, Ciências e Letras de Ribeirão Preto, da Universidade de São Paulo (USP) Ribeirão Preto.E-mail: erikaandra@hotmail.com

** Doutor em Educação pela Universidade de São Paulo (USP). Professor do Curso de Pedagogia e do Programa de Pós-graduação em Educação da Faculdade de Filosofia, Ciências e Letras de Ribeirão Preto da Universidade de São Paulo Ribeirão Preto.E-mail: mvcunha2@hotmail.com 
initiated in the 20th century, and following one of the lines of inquiry in the Rhetoric and Argumentation in Education Research Group (USP/CNPq), this text discusses the notions of language and of linguistic agreements in Aristotle's discourse. Emphasizing the essentiality of the logos to actualize a psyche which is able to conduct collective bargaining and to elaborate virtuous internal speeches, Aristotle places education within an artistic, poetic, and rhetorical universe. The Aristotelian educational project offers strength and power to human beings, aiming at improving personal experience in community and at consolidating individual happiness, which is inseparable from the construction of the ideal polis.

Keywords: Aristotle. Language. Education. Art. Rhetoric.

\section{Lenguaje y acuerdos lingüísticos en Aristóteles: contribuciones para una educación artística, poética y retórica}

Resumen: Adepto al movimiento de revisión de la filosofía aristotélica iniciado en el siglo XX, y según una de las líneas de investigación del Grupo de Investigación Retórica y Argumentación en Pedagogía (USP/CNPq), este texto aborda las nociones de lenguaje y acuerdos lingüísticos presentes en el discurso de Aristóteles. Al reconocer el logos como esencial para la actualización de una psique apta a conducir acuerdos colectivos y desarrollar discursos internos ejemplares, Aristóteles sitúa la educación en el ámbito de un universo artístico, poético y retórico. El proyecto educacional aristotélico ofrece fuerza y poder al hombre, con el mirada de mejorar su experiencia en colectividad y fortalecer a una felicidad individual, que es inseparable de la construcción de la polis ideal.

Palabras clave: Aristóteles. Lenguaje. Educación. Arte. Retórica.

\section{Introdução}

O movimento de revisão das concepções aristotélicas desencadeado no século XX afastou Aristóteles de interpretações teológicas até então hegemônicas. Alguns estudos enfatizaram sua aproximação com a filosofia prática que, diferentemente da ciência demonstrativa, discorre 
sobre a dialética e a retórica, apresentadas como meios de viabilizar uma forma de racionalidade própria das ciências morais - o direito, a ética, a política e a economia (BERTI, 1997). Outros voltaram-se para a metafísica aristotélica, esclarecendo seu distanciamento da transcendência formal platônica e a identificando como ciência que discorre sobre o ser e sua substância, entendidos, respectivamente, como matéria sensível e concreta, disposta em determinado formato, e como discurso capaz de explicar a espécie biológica do ser (ANGIONI, 2008; CASTRO, 2008). Outros, ainda, dedicando-se ao campo da linguagem, defenderam que o Estagirita compreendeu o caráter circunstancial da oralidade, mostrando haver povos com diferentes formas de expressão linguísticas, e, além disso, teorizaram sobre a predicação, ou significação, como fenômeno resultante de convenções (ANGIONI, 2006; MATA, 2013).

Considerando esses desenvolvimentos, o presente texto examinará as noções de linguagem e acordo linguístico em Aristóteles, procurando evidenciar a influência que tais concepções exercem nas formulações educacionais do filósofo, destacando a sua relevância como elemento central no processo de formação e no desenvolvimento discursivo e deliberativo do homem.

Mostraremos, inicialmente, que Aristóteles define o homem como ser que possui características biológicas específicas, sendo potencialmente capacitado para a predicação e a discursividade, do que resultam bases seguras para caracterizar a linguagem como fenômeno social, cuja gênese repousa nos acordos linguísticos estabelecidos por indivíduos que experienciam o mesmo mundo natural. Em seguida, abordaremos a acentuada confiança que Aristóteles deposita no poder da palavra, considerando que a comunicação possibilita o discernimento do bem e do mal, do justo e do injusto, impelindo as pessoas a construírem suas principais forças psíquicas, as virtudes intelectuais e morais.

Entendendo essa valorização do logos como elemento sine qua non à atualização de uma psique capaz de efetuar acordos e convenções, como também à elaboração de discursos internos sensatos e virtuosos, 
procuraremos mostrar que Aristóteles situa a educação, realizada informalmente na comunidade ou formalmente nas instituições públicas, no âmbito de um universo artístico, poético e retórico voltado à formação da capacidade de deliberar sobre temas concernentes à moral. Na conclusão, argumentaremos que o caráter artístico, poético e retórico do projeto educacional aristotélico abre caminho para a consolidação da felicidade individual e a concretização da polis ideal, assim, fortalece o vínculo entre o indivíduo e a sociedade, uma vez que a busca pelo bem de todos tem valor para cada pessoa em particular, pois todos se reconhecem - percebem seus desejos e suas vozes - nas políticas que visam ao bem comum.

\section{Uma concepção de linguagem}

Segundo Aristóteles, o homem é um ente sensível e concreto, composto por carne e osso dispostos de certa maneira ou formato. Para explicar a unidade total dos compostos orgânicos humanos, demonstrando porque a combinação de tal matéria com tal formato origina um ser com determinadas funções, tornando-o aquilo que ele é, o filósofo recorre à apresentação da substância alma. Como elemento comum a todos os seres da espécie, a alma abarca as capacidades nutritiva, perceptiva, imaginativa, raciocinativa e de movimento, possibilitando as condições necessárias para o indivíduo nutrir-se, ter e usar órgãos sensoriais, moverse, crescer, reproduzir e decair, pensar, imaginar e deliberar (ANGIONI, 2008; CASTRO, 2008).

Abordando a matéria, o formato e a substância alma, Aristóteles define as propriedades do corpo humano, as características básicas que unem todos os indivíduos da espécie, e as potencialidades de desenvolvimento que habilitam todos os homens a atingirem suas melhores realizações. Tais elementos compõem uma forma biológica que é transmitida e herdada por meio da reprodução. Como o aparato próprio do humano, enquanto potência, não é suficiente para atualizar naturalmente 
suas próprias possibilidades, o Estagirita estende a sua definição inicial de homem, concebendo que “o ser humano é, por natureza, um ser social”, e, portanto, depende das condições objetivas e relacionais para atualizar as faculdades e potencialidades básicas inerentes à espécie e adquirir outras capacidades e habilidades culturais (Ética a Nicômaco, I, 7, 1097b10-15).

Os humanos podem atualizar potências que lhes permitem fazer coisas, tal como outros animais, mas as oportunidades de aprendizagem junto aos mais experientes os capacitam a fazer o que nenhum outro animal consegue, como o uso pleno da racionalidade deliberativa. Aristóteles refere-se a uma idiossincrasia humana que, iniciada pela atualização da faculdade da imaginação - formando imagens internas relativas aos conteúdos sensoriais dos pragmata percebidos na experiência -, permite que o homem desenvolva uma memória bem mais complexa que a dos outros². Essa memória envolve não só a lembrança de uma figura, mas também a sua recordação, e promove vínculos entre as imagens que são registradas interiormente, isto é, as imagens que se tornam afecções da alma ${ }^{3}$. Desse modo, mesmo as lembranças mais distantes são readquiridas e conectadas por meio de percepções ou ideias intermediárias (ROSS, 1906).

Aristóteles relata que o homem "tem os lábios moles, carnudos e com capacidade de se afastarem”, o que o dota de uma excelência, a “expressão verbal”; em comparação com todos os outros animais, o homem é o que tem “a língua mais flexível, mais mole e mais larga”, permitindo-lhe “a articulação dos sons e a produção da linguagem” (Partes dos animais, II, 17, 660a). Outras espécies animais participam da “voz”, podendo emitir

2 Pode-se associar a ideia de pragma - e, portanto, pragmata - a coisas/objetos individuais, mas também a fenômenos, estados de coisas e fatos complexos. Ver Angioni (2006, p. 84).

3 Ao ser afetado pelos estímulos do ambiente, o homem pode apreender o conteúdo sensorial das coisas vivenciadas - isto é, dos pragmata - tendo o seu estado interior alterado. Quando os estados internos dos indivíduos se alteram, ocorrem as afecções da alma (MODRAK, 2001). 
sinais “da dor e do prazer" e fazendo-se "compreender uns aos outros". Todavia, somente o homem tem o “dom da palavra”, sendo o único ser a utilizar a palavra como símbolo - ou como um som significativo - para conferir significado aos sentimentos, dizer que algo existe, declarar o que algo é, diferenciar o bem do mal, discernir o que é útil ou prejudicial, compreender o que é justo ou injusto etc. (A política, I, 1, 1253a5-20).

Tais especificidades biológicas são centrais para a atualização e o desenvolvimento da linguagem; trata-se de uma potencialidade que responde de modo especial pela interrupção da contiguidade entre humanos e demais animais, sendo instrumento para todos os outros tipos de realizações pessoais e coletivas (CASSIN, 1999). Aristóteles sugere que a faculdade da imaginação funciona como primeiro alicerce para a emissão da voz como "som significativo", uma vez que a imagem formada internamente acerca de um pragmata pode ser comparada a um retrato que simboliza coisas, estados ou fenômenos do mundo real (De anima, II, 8, 420b27) 4 . Por exemplo, uma pessoa pode identificar que uma tocha de fogo, estando em movimento, representa a presença do inimigo, pois a imagem - tocha acesa em deslocamento, significando o inimigo - foi impressa na alma, sendo recuperada em outros momentos, mesmo naqueles em que o fogo não está presente (De anima, III, 7, 431b2).

Possibilitado pela aquisição da memória, o movimento interno de recordação, que é "parecido com o de um silogismo", surge na narrativa aristotélica como segundo alicerce para o desenvolvimento da significação, pois, envolvendo a ligação entre coisas cujos conteúdos se exprimem por imagens e/ou palavras, possibilita que os indivíduos realizem predicações, mentais ou públicas, chegando à formulação de percepções mais elaboradas, e mesmo originais, acerca de elementos ainda desconhecidos (De memória, II, 453a5-20). O frequente exercício da recordação viabiliza, consequentemente, a origem da experiência no homem, representando um estágio mais avançado do pensamento que

4 Ver também Modrak (2001). 
passa a formular juízos universais; o intelecto, elaborado em meio ao logos, pode alcançar o desenvolvimento da arte, no âmbito do criar ou fabricar, e da ciência, no âmbito do estudo dos primeiros princípios, permitindo ao indivíduo conhecer não só os fatos do mundo, mas também seus porquês (Analíticos posteriores, II, 19, 100a5-10).

Identificando forte relação entre a gênese da linguagem e fatores orgânicos biológicos, o discurso aristotélico vai além, apresentando o caráter convencional do processo de elaboração das significações e do sistema linguístico. Primeiramente, o filósofo aborda a cognoscibilidade das coisas do mundo: o conhecimento advém das investigações acerca dos inteligíveis e não do desvelamento de Formas metafísicas. Em seguida, lembra que as coisas percebidas afetam os estados internos dos indivíduos, possibilitando-lhes apreender, criar imagens e reter lembranças de seus principais conteúdos sensórios; assim, todas as "afecções da alma” podem ser significadas pela palavra, por um "símbolo”, que é fruto de “convenção”, tornando a oralidade e a escrita signos acordados social e circunstancialmente (Da interpretação, I, 16a1-20).

Sendo coerente com sua visão de ciência natural, cujos estudos empíricos e procedimentos indutivos remetem a observações detalhadas dos particulares, Aristóteles não acredita na possibilidade de haver percepções infinitas ou absurdamente divergentes acerca dos pragmata, pois suas formas possuem certa estabilidade. As pessoas podem observar, sentir e apreender aspectos convergentes dos objetos e fenômenos. É possível que determinada pessoa seja impressionada, mais do que outra, por certo aspecto do real, retendo percepções diferentes sobre as coisas. Nessas ocasiões, as pessoas precisam empreender esforços para alcançar consensos acerca dos conteúdos percebidos, construir acordos sobre o que poderão eleger como mais representativo da realidade observada e analisada; e é nesse momento que a palavra, resultante de convenção, cumpre sua função social (MODRAK, 2001).

Segundo Aristóteles, se é "por indução que adquirimos conhecimento das premissas primárias”, é também desse modo que “os con- 
ceitos gerais nos são transmitidos pela percepção sensorial” (Analíticos posteriores, II, 19, 100b1-5). A indução é um dos tipos de argumento dialético, no qual a conversa ocupa posição central no desenvolvimento do raciocínio, sendo igualmente uma metodologia convincente por ser “compartilhada” pelas pessoas (Tópicos, I, 12, 105a10-20). Por isso, além da observação e da vivência em meio aos pragmata, a conversa - ou algum tipo de comunicação, mesmo que incipiente - é fundamental para a elaboração dos conteúdos sensórios dos objetos e dos fatos percebidos no mundo, para os quais também é acordado um símbolo oral e escrito.

Nas Categorias (VII, 7b10-15), nota-se a premência de os humanos nomearem os objetos e fatos do mundo, haja vista que, havendo "um nome para ser manuseado”, torna-se fácil indicar a relação entre as coisas, ou mesmo fazer considerações sobre suas qualidades, posições, quantidades etc. Aristóteles entende que a convenção de um nome, ainda que embrionariamente, amplia o espectro comunicativo e estimula o movimento de recordação, permitindo a ligação das características da imagem de um pragmata às de outros, facultando as conversas públicas e as conversas internas - ou solilóquios -, o que ajuda as pessoas a concordarem que algo observado é um isto com tal formato e tais qualidades. Esse processo de vocalização simbólica e de acordos pode ser aprimorado até que a atividade de significação chegue a uma condição estável, firmando, portanto, uma relação entre as coisas e as palavras que as definem, o definiendum e o definiens, com base na semelhança entre os significados e as realidades (MODRAK, 2001).

$\mathrm{O}$ reconhecimento de que o Estagirita apresenta a linguagem como um fenômeno social, decorrente de acordos linguísticos estabelecidos por indivíduos que experienciam eventos de um mesmo mundo natural, possibilita outro entendimento de uma célebre enunciação aristotélica, segundo a qual as afecções da alma, das quais os nomes são signos, são "idênticas para todos”, como são também idênticos "os objetos de que essas afecções são as imagens” (Da interpretação, I, 16a1-10). O que o filósofo indica, simplesmente, é que as pessoas podem observar um 
fato desconhecido $\mathrm{C}$ e podem dizer, mediante acordo, que as qualidades tais são as que mais o representam, e que, portanto, "C é a lua”; agindo assim, as pessoas admitem que o observado não pode ser assim e, ao mesmo tempo, não-assim, mesmo porque qualquer significado elaborado em comum deve fazer sentido para todos os envolvidos, esclarecendo a existência da coisa para a comunidade e viabilizando a continuidade das atividades discursivas (Metafísica, IV, 4, 1006a20-30).

Para Aristóteles, o significado de um termo é determinado pelas qualidades do próprio pragmata, que tem uma ontologia, uma composição sensível e concreta: material, formato físico e uma funcionalidade. A observação dos sensíveis vem em primeiro lugar na escala investigativa do conhecimento, e o homem, por ter linguagem e a racionalidade como potências, possui a capacidade de perceber quaisquer composições. Por isso, o Estagirita afirma que a linguagem deve ser usada como instrumento para os homens tentarem apreender, acordar e expressar a ontologia das coisas. Como se lê na Metafísica (IV, 8, 1012b5-10), esse processo não remete à descoberta de uma Forma imanente e transcendental, não visa descortinar que “alguma coisa seja ou não seja”, mas diz respeito ao estudo do sensível mediante o uso da linguagem, culminado na afirmação de "algo que tenha significado".

Angioni (2006, p. 84) sustenta que Aristóteles não quis afirmar que as afecções "surgem na alma por um milagroso processo de recepção da forma das coisas, de maneira absolutamente independente de qualquer processo de formulação linguística”, como se "todos os homens tivessem na alma as mesmas concepções a respeito das mesmas coisas”; seu objetivo era mostrar que a comunicação entre os homens requer "pelo menos um mínimo de acordo quanto às afecções e às coisas significadas”. Corroborando essa interpretação, Mata (2013) diz que, se um grupo de pessoas se encontra diante de um rolo de pergaminho com alguns cantos da Ilíada, por mais distintas que sejam as suas descrições, ainda assim haverá certa identidade na percepção do objeto; se não existir o acordo de um núcleo idêntico, mesmo que fluido ou instável, não haverá continuidade discursiva. 
Colocando em primeiro plano a elaboração de um "discurso sensato" sobre as coisas, uma vez que as condições impostas pelo próprio conhecimento são decorrentes da discursividade, a filosofia aristotélica defende uma "dialética forte" o bastante para levar as pessoas a acordos e convenções, advogando que tudo o que é expresso linguisticamente deve fazer sentido "para si e para o outro" (CASSIN, 1994, p. 321). O discurso aristotélico renega a perspectiva platônica, bem como a de escolas que concebem a necessidade de um movimento do espírito para alcançar o conhecimento verdadeiro; afasta-se, também, de concepções que afirmam a existência de um nome natural relativo a cada coisa do mundo das aparências, cabendo a alguns homens - dotados de certa arte - a tarefa de descobrir os nomes e seus significados, por meio de um movimento da alma que se identifica com o movimento das coisas.

\section{Linguagem, acordos linguísticos e formação do pensamento}

Aristóteles considera que a finalidade humana será mais perfeita se cada indivíduo desempenhar certa função que supere todas as funcionalidades de seus membros particulares, ultrapassando o mero ato de viver, a vida sensitiva e perceptiva, as atividades vitais, ou qualquer função compartilhada por animais e plantas em geral (Ética a Nicômaco, I, 7, 1097b 30-1098a1). Tal função é o "exercício ativo da faculdade racional”, pois a principal atividade de um indivíduo é agir guiando-se pela inteligência [nous] (Ética a Nicômaco, I, 7, 1098a5-10). O desenvolvimento do pensamento, da racionalidade, da inteligência, enfim, de toda psique implica tanto o alcance das virtudes intelectuais, cujos estados progressivos compreendem "a arte, o conhecimento científico, a prudência (sabedoria prática), a sabedoria filosófica e o entendimento", quanto a obtenção das virtudes morais (Ética a Nicômaco, VI, 3, 1139b15-20).

Como a atualização de quaisquer virtudes especificamente humanas não é “conferida por algum favor divino ou mesmo pela sorte” (Ética a Nicômaco, II, 1, 1103a15-25), somente uma educação política pode au- 
xiliar o homem no percurso do seu desenvolvimento (A política, VII, 15, 1336a15-20). "O fim da arte e da educação, em geral”, diz o Estagirita, "é substituir a natureza e completar aquilo que ela apenas começou"; não se trata de aniquilação ou troca, mas do reconhecimento de que o sujeito pode fazer parte de outros estágios do desenvolvimento, os quais expressam uma contínua atualização da função humana a partir da forma biológica (A política, VII, 15, 1337a1). Assim, "se a vontade e mesmo os desejos se manifestam nas crianças desde os primeiros dias de existência”, o "raciocínio e a inteligência só se mostram naturalmente após um certo desenvolvimento" (A política, VII, 13, 1334b20-25). Isso ocorre porque os hábitos conduzem um indivíduo a "comportar-se de uma outra maneira" sempre, ou na maioria das vezes, de modo que a disposição habitual se configura como "uma espécie de [segunda] natureza” (Ética a Nicômaco, II, 1, 1103a20-25).

Aristóteles especifica que uma educação política geral, com ações capazes de desenvolver o pensamento, dando ao homem o status de homem, deve propiciar vivências em meio a condutas virtuosas, ao convívio com os mais experientes, à participação em transações com semelhantes e à prática em determinada arte; também são relevantes as ações relacionadas ao ensino promovido por meio de cursos, teorias, palestras ou quaisquer outros projetos instrutivos. Todas essas atividades constitutivas do pensamento têm em comum o fato de serem desenvolvidas por meio da linguagem, a qual opera para estabelecer acordos, efetuar a nomeação de alguma coisa, indicar que $\mathrm{A}$ é melhor do que $\mathrm{C}$, explicar um modo de fazer, demonstrar que algo é X, possibilitar debates sobre bens públicos etc. Por serem discursivas, e, portanto, portadoras dos significados relativos ao costume social, tais atividades possibilitam o vínculo entre a hominização e o desenvolvimento do pensamento, de um lado, e linguagem como elemento essencial à formação do pensamento, de outro, indicando que o que responde pela formação do homem, em última instância, não é outro fator que não a linguagem. 
Quando Aristóteles aborda a importância de as pessoas nomearem as coisas, também está se referindo à centralidade do logos para desenvolver o pensamento. Uma pessoa que conhece o bode e o cervo, cujos signos simbolizam seres com determinadas características, pode predicar um terceiro ente e nomeá-lo bode-cervo, indicando a imagem de um animal com conteúdos de ambos; essa pessoa parte de significados conhecidos para criar conceitos novos, recriando seus esquemas mentais (Da interpretação, I, 16a10-15). Na perspectiva aristotélica, quando as pessoas operam na esfera de coisas conhecidas e nomes, utilizam o "pensamento antedeclarativo” que, a despeito de não objetivar uma definição verdadeira, como acontece no raciocínio declaratório, já envolve “certa conexão e certa conjunção entre diversos itens", chegando a "formulações proposicionais” em que o é está “circunscrito ao plano da coerência interna das conexões que pensamos” (ANGIONI, 2006, p. 87).

Considerando o pensamento antedeclarativo, no qual a enunciação de um nome supõe implicitamente uma relação proposicional entre o nome e certas noções, pode-se dizer que uma criança que frequentemente vê pratos e escuta o nome prato passará a associar tal palavra com a imagem do referido pragmata, alcançando o entendimento de que o som prato indica a existência de um objeto com características tais e tais. Com o tempo, tendo aprendido os significados e os nomes de várias coisas, essa criança, além de conseguir conversar com mais destreza, comunicando fatos, acontecimentos, vivências, vontades e sentimentos, também poderá começar a conversar consigo, fazendo ligações entre os conteúdos das coisas de maneira mais autônoma, e, principalmente, iniciando raciocínios envolvendo ponderações sobre desejos e escolhas (ANGIONI, 2006; MODRAK, 2011).

Aristóteles analisa a ocorrência das predicações internas a partir daquilo que os indivíduos veem e escutam, destacando que tais predicações possibilitam aos indivíduos elaborar imagens e significações com níveis cada vez mais aprimorados de generalizações. Ao valorizar a existência de um sistema linguístico criado pelos homens no âmbito 
de práticas sociais, ao destacar o caráter imprescindível das conversas sociais para propiciar o conhecimento das coisas do mundo, o filósofo enaltece a aprendizagem do uso da língua em meio à vida, bem como a existência e o trabalho do discurso interno, que contribui para a formação, organização e desenvolvimento do pensamento.

Retomando a tradição de que o bem e o belo representam a felicidade, e que a vida feliz é um fim ético a ser almejado pelos indivíduos e pelo Estado, Aristóteles esclarece que a felicidade é a participação em uma vida cujas atividades são sempre guiadas pelo exercício racional especulativo, no qual “as virtudes cooperam com (ou envolvem) a justa razão” (Ética a Nicômaco, VI, 13, 1144b25-30). O filósofo estabelece que a causa geradora da felicidade se refere, especialmente, ao exercício da prudência. A racionalidade embebida de prudência, ou sabedoria prática, "leva os homens a fazerem muitas coisas contrárias ao hábito e à natureza”, pois “eles se convencem de que é melhor fazer de outra forma” (A política, VII, 12, 1332b5-10). Isso não significa que os homens prudentes separem dicotomicamente a cognição da paixão; pelo contrário, adentrando em um discurso interno, eles usam a primeira para ponderar, deliberar e escolher, de modo a aceitar conscientemente as condições de seus desejos, ou persuadir e canalizar as paixões para outras vias, cooperando com “o que é bom e proveitoso para si”, assim como "para o bem-estar em geral” (Ética a Nicômaco, VI, 5, 1140a25-30).

Em seus tratados éticos, políticos e retóricos, Aristóteles destaca justamente o papel da linguagem na formação do caráter prudente-portanto, sábio - lembrando que as oratórias, exercitadas de diferentes maneiras, "tocam mais de perto ao homem do que o uso de seus membros" (Arte retórica, I, 4, 12). O filósofo acredita que um cidadão pode empregar a fala para influenciar seus pares e intervir no curso de seus desenvolvimentos, uma vez que o logos atua na formação dos hábitos pessoais e na constituição de uma segunda natureza humana. Aristóteles acredita ser necessário pensar na educação integral das crianças pequenas e dos jovens, bem como na participação dos jovens em atividades junto aos 
mais experientes, ou mestres; tanto o ambiente discursivo educacional criado intencionalmente, quanto as vivências educativas informais que comunicam modos de ação e de pensar considerados adequados, são determinantes para o desenvolvimento do pensamento e das virtudes.

Aristóteles também considera imprescindível formar a psique humana para dominar o logos; é preciso "estar à altura de persuadir”, não para "nos entregarmos indiferentemente", uma vez que "não se deve persuadir o que é imoral”, mas para termos clareza sobre as questões examinadas e para "estarmos habilitados a reduzir por nós mesmos ao nada a argumentação de um outro, sempre que este em seu discurso não respeite a justiça” (Arte retórica, I, 4, 12). Tais reflexões conduzem à imagem de um filósofo que se ocupa não apenas dos aspectos lógicos da linguagem, mas que trabalha enfaticamente o uso dialético envolvido na prática linguageira, lembrando que a contrapartida da dialética é a retórica. Aristóteles é cônscio de que, exceto o que se encontra nos domínios da matemática, os primeiros princípios da física, da metafísica, da ética, da política etc. dependem da atividade linguística da indução, a qual, quando não se mostra suficiente, requisita a atividade linguística de persuasão. Sendo o conhecimento sobre o ser humano um produto da linguagem, o aprimoramento das pessoas também decorre dos acordos linguísticos produzidos dialética e retoricamente, ou seja, elaborados socialmente.

Aristóteles, portanto, confia no poder do logos para conhecer, instrumentalizar e melhorar o humano; confiança que se acentua porque a palavra possibilita o discernimento do bem e do mal, do justo e do injusto, impelindo as pessoas a construírem as suas principais forças psíquicas, as virtudes intelectuais e morais, destacando-se a capacidade para agir prudentemente. O Estagirita também entende que a comunicação constitui o Estado, pois os discursos e debates dialéticos são meios essenciais para a elaboração das leis, das artes, do sistema educativo e da própria comunidade política (A política, I, 1, 1253a15-20). Segundo Eire (2010, p. 342), a narrativa aristotélica sobre o homem e o Estado situa-se na esfera da incerteza, pelo fato de conceber que ambos são 
frutos da retoricidade da linguagem, cuja dialética busca mover o pensamento em sua relação com as paixões. Os processos formativos e as trajetórias desenvolvimentistas consumados pela educação formal e por ações informais não se circunscrevem a métodos "geométricos", sendo permeados por "estratégias psicológicas e estéticas", permanecendo abertos a possibilidades e mudanças.

Embora valorize o desenvolvimento da racionalidade humana, Aristóteles não restringe sua filosofia à alma pensante, ou seja, não elege a psique como único elemento decisivo na instituição do homem. Destacando o poder mobilizador dos discursos para instrumentalizar o intelecto, preparando as pessoas para o debate e a deliberação, o Estagirita se apresenta como portador de uma filosofia inovadora, considerando-se o ambiente intelectual e social de sua época. Para Cassin (1994), Aristóteles pode ser visto como um precursor do pensamento contemporâneo porque é possível identificar em suas formulações a projeção de uma virada linguística ${ }^{5}$.

\section{O universo artístico, poético e retórico da educação}

Segundo a teorização de Aristóteles, as ações voltadas para o fomento da racionalidade virtuosa - representando o bem, a felicidade e a função que todo ser humano deve atualizar - pressupõem atividades educativas e práticas instrutivas desde a mais tenra idade e, principalmente, o oferecimento de formação integral para os jovens, administrada pelo Estado e em comum, sendo única para todos (A política, VIII, 1,1337a20-25). Na concepção do filósofo, todo processo educativo implica a comunicação

5 A expressão virada linguística (reviravolta linguística ou giro linguístico, dependendo da tradução) indica o ponto histórico, aproximadamente entre o final do século XIX e início do século XX, em que certos pensadores conceberam que uma compreensão mais adequada da linguagem poderia ajudar a solucionar os problemas filosóficos, epistemológicos e humanos. Ver Auroux (1998) e Ghiraldelli Jr. (2003). 
e o uso da linguagem, porque o homem tem "o dom da palavra”, e o logos é o que possibilita "compreender o que é útil ou prejudicial, e, em consequência, o que é justo ou injusto”; a "comunicação” das valorações e acordos humanos é o que "constitui precisamente a família do Estado" (A política, I, 1,1253a5-20).

A educação sugerida pelo Estagirita pode ser definida como comunicação ou prática linguística, o que é coerente com as suas proposições relativas à linguagem como fenômeno social e imprescindível para a instituição humana. Ao especificar que as crianças pequenas devem ser educadas na casa paterna até os sete anos, evitando contato com os escravos, Aristóteles defende a convivência da criança com pessoas que têm acesso ao logos e que, portanto, o detêm; a participação em um meio linguístico que pode ser enriquecido com leituras de contos e fábulas constitui, para o pequeno cidadão, verdadeira porta de acesso ao universo humano (A política, VII, 15, 1336a5-40). Condenando qualquer contato dos educandos com palavras e pinturas “indecentes” e “obscenas”, Aristóteles reforça a necessidade de cuidar das significações transmitidas na comunidade, uma vez que os signos formam os hábitos de uma segunda natureza humana (A política, VII, 15, 1336b5-40).

Aristóteles alega que a educação formal dos jovens deve ser "o meio de adquirir muitos outros conhecimentos”, e, por isso, não pode ser mecânica, tampouco pode impedir a liberdade do pensamento ( $A$ política, VIII, 3, 1338a35-40). O logos deve estar presente em todos os processos instrutivos, aprimorando a autonomia para a participação em atividades deliberativas, realizadas no contexto privado do pensamento ou no âmbito político da ágora; todo cidadão formado, independentemente do cargo ocupado na cidade, deve possuir certa inteligência prática para resolver questões circunstanciais de modo justo e prudente; também precisa ter domínio linguístico suficiente para defender posicionamentos diante seus pares.

Se uma pessoa aspira a um conhecimento científico da política, diz o filósofo, faz-se necessária a experiência prática e o estudo (Ética 
a Nicômaco, X, 9, 1181a10-15); na relação prática, a conversa está presente, pois os mestres narram suas experiências ao mesmo tempo em que atribuem valor às atitudes e disposições dos aprendizes. Nos estudos - leituras, palestras, manuais, discussões, elaborações indutivas etc. - a presença da linguagem é ainda mais inquestionável. Mesmo em atividades práticas ou em experiências naturais, com recursos didáticos diversos, bem como em exercícios de movimentação física, a relação linguística se faz imprescindível; de nada adianta um excelente vigor muscular, se o indivíduo não consegue elaborar o raciocínio prático que lhe permita identificar o que pode ser um ato de coragem, ou de justeza.

Aristóteles explica que a arte é "uma qualidade racional concernente ao criar"; a arte envolve "um verdadeiro processo de raciocínio", ocupa-se em "trazer alguma coisa à existência” mediante "estudo" e almeja "um fim que é distinto do ato de criar” (Ética a Nicômaco, VI, 4, 1140a10-15). No processo artístico, o pensamento e a produção admitem a variação, motivo pelo qual são mais bem realizados por pessoas com sabedoria prática, também reconhecidas como prudentes e eficientes na deliberação em geral. Se na medicina o exercício do médico é uma arte, a atividade do formador ou treinador, no âmbito da educação, também pode ser vista como tal: trata-se da arte de educar - especialmente pela comunicação - a segunda natureza humana, envolvendo o exercício da prudência e um sistema de tratamento cujo objetivo é zelar pelo aprimoramento das faculdades e virtudes pessoais (Ética a Nicômaco, X, 9, 1180b10-30). A geração artística das qualificações individuais reside na esfera da incerteza, pois, embora os formadores sigam algumas regras benéficas e deliberem sobre a própria ação, a escolha das ferramentas a serem utilizadas, bem como o modo de operá-las, "não produz sempre os mesmos resultados” (Ética a Nicômaco, III, 3, 1112b1-15).

Segundo Chambliss (1987, p. 133), Aristóteles identifica o homem como pensador e, por isso, "criador mestre” da natureza humana e da polis; é o próprio homem que, tal como um artista, elabora a (re)criação da realidade por meio da investigação e simbolização do mundo, bem 
como pelas ações educativas propostas; tais vias, sem exceção, comportam conversas coletivas e interiores que levam o homem a pensar seus desejos, ponderar, significar e escolher. A criação do bem humano, por estar nas mãos artísticas do homem, não diz respeito a um sonho irrealizável, mas a uma execução plenamente passível de ser empreendida, uma "atividade real”, que leva em conta as possibilidades da espécie humana, os dados da própria realidade empírica, o uso do pensamento discursivo ou da dialogicidade junto aos pares e, ainda, as operações do intelecto (PERINE, 2006, p. 71).

Aristóteles não tem uma obra diretamente voltada para as características da arte educativa, realizada formal ou informalmente; n’A Política, seu interesse é focalizado nas matérias que são institucionalmente ministradas na instrução dos jovens. Apesar disso, é válido considerar que vários de seus escritos abordam elementos relativos à educação, de modo amplo, como é o caso dos Tópicos e de Analíticos anteriores, que ensinam como os homens podem construir conceitos sólidos sobre as coisas e demonstrá-los. Reconstruindo o pensamento pedagógico aristotélico, tal como diante de um quebra-cabeças, também é válido considerar que, para o filósofo, a arte de educar, além de ser linguística, abarca, a despeito de suas peculiaridades, características de outras artes, em especial os qualificativos próprios da poética e da retórica.

Aristóteles afirma que o homem é um ser que deseja, imagina, raciocina e que se move (De anima, III, 10, 433a9-433b21); sua natureza o predispõe a desejar seguir em frente; de posse de um primeiro motor - uma genética inerente à espécie - todo homem anseia atualizar suas potencialidades básicas e ultrapassar os limites da biologia para conquistar novos feitos no plano cultural, social e político. Os desejos, que são responsáveis por impulsionar as ações humanas, são movidos pela imaginação raciocinativa, pois o pensamento reflete sobre os desejos e os mobiliza seguir em determinada direção. Sendo assim, as ações capazes de potencializar o crescimento humano são prioritariamente aquelas que se fazem permeadas por uma forma de comunicação que toca mais de 
perto os desejos, que provoca o impulso para criar, para fomentar estados psicológicos propícios ao vir a ser, oferecendo, além disso, instrumentos para a conquista de bens.

Todas essas características estão presentes nas ações realizadas artisticamente, em especial nas artes efetivadas nos universos estéticos e persuasivos da poética e da retórica. Pelo fato de tais artes tocarem a alma humana, cada qual à sua maneira, ambas têm potencial educativo, devendo fazer parte da vida do cidadão grego. Ambas fazem uso de meios comunicativos que acentuam a mobilidade dos desejos e dos raciocínios e, consequentemente, dos próprios seres humanos, os conduzindo sempre adiante. A poética e a retórica propiciam esclarecimentos sobre os significados elaborados socialmente, envolvendo a discussão sobre o que uma coisa é e sobre o que queremos ou podemos alcançar. Por isso, essas duas artes contribuem para a contínua (re)elaboração dos acordos linguísticos, os quais, gerados socialmente, influenciam os rumos da humanidade.

O poeta, aquele que atua em diferentes gêneros de produção artística envolvendo a linguagem, até mesmo a dança ou a música vocal, é um "imitador”, tal qual o pintor ou "qualquer outro criador de figuras”, porque a sua atuação resulta em criações cujos pontos de partida são fatos, pessoas, circunstâncias e condições materiais da realidade; o que ele produz expressa os diferentes modos de ler ou significar a vida (Arte poética, XXVI, 2). Não obstante, complementa o Estagirita, partindo do que conhece sobre o mundo real, o poeta também pode ser autor de coisas "segundo a verossimilhança”, acreditando que todas as suas projeções são verdadeiramente possíveis (Arte poética, IX, 1$)^{6}$. De modo similar, a educação trata das coisas como elas são, como os outros dizem que são, como parecem ser, ou até mesmo como deveriam ser. Realizada em uma dimensão linguística e comunicativa que é poética, a arte educativa

6 Para Aristóteles, as artes plásticas, como as artes poéticas, são imitativas. As duas abordam as coisas como elas são e como deveriam ser (VOILQUIN; CAPELLE, 1964). 
almeja construir um homem que, além de ser capaz de apreender a realidade fenomênica, utilize o logos para criar possibilidades que sejam boas, belas, amáveis e, principalmente, passíveis de serem alcançadas, para si e para seu meio.

No conjunto do pensamento aristotélico, a poética é uma das ramificações da possibilidade; a outra é a retórica (MEYER, 2000). Aristóteles explica que a arte retórica, aliada à dialética, tem o objetivo de auxiliar os indivíduos em suas decisões, considerando que algo pode ser ou não ser bom. As técnicas indutivas da dialética, particularmente, possibilitam inferir sobre o que é melhor e mais adequado; a retórica, por sua vez, é essencial para os indivíduos saberem utilizar os meios de persuasão sobre aquilo que se concluiu ser o bem. Em um ambiente educativo retórico, a linguagem e a comunicação representam conteúdos que precisam ser estudados e compreendidos em suas funções sociais, uma vez que instrumentalizam, dão poder e força para as pessoas apresentarem o “verdadeiro" e o “justo”, e poderem defender que são eles “melhores que seus contrários” (Arte retórica, I, 4, 12-14).

Em prol de uma formação humana voltada para a retoricidade, Aristóteles posiciona seu discurso em torno da metáfora homem-medida, a qual traduz a ideia de que o homem, visto como ser pensante e reflexivo, é a medida de suas próprias ações morais, o que envolve suas condutas, comportamentos, valorações, juízos, deliberações, escolhas etc ${ }^{7}$. Assim concebido, o homem é responsável por seu próprio desenvolvimento e pelo desenvolvimento da humanidade. Entendido como “união de desejo e intelecto”, o ser humano é “gerador da ação”, é aquele que busca e evita, delibera, entende, escolhe, age e modifica o próprio eu, bem como os outros e o Estado (Ética a Nicômaco, VI, 2, 1139b5-10).

7 A metáfora homem-medida decorre da seguinte analogia: o homem é quem avalia o curso de suas próprias ações (tema), assim como a medida é o que serve para avaliar grandezas físicas (foro). 
Com origem na sofística, mais precisamente em Protágoras, a metáfora homem-medida contém as seguintes ideias: todo homem é igual aos demais, devido à sua natureza; é possível modificar o homem pela transformação de seus hábitos; cada pessoa, em particular, influi, de maneira relevante, na elaboração de juízos; é possível chegar ao conhecimento daquilo que é mais útil, conveniente, adequado e oportuno, levando em conta as necessidades do público, os cidadãos e a própria cidade (REALE, 2002). Com essas teorizações, Aristóteles discorre acerca de um homem reflexivo que faz uso do discurso interior para perceber e diferenciar; que utiliza o logos para debater com seus pares os conteúdos da percepção, visando alcançar consensos sobre os percursos mais adequados a serem seguidos, negando qualquer tentativa de redução da realidade ao que é apreendido pelos sentidos.

Para Aristóteles, a arte, a poética e a retórica potencializam a comunicação, viabilizando os acordos derivados de práticas linguísticas; fazem isso na medida em que o logos, além de ser declarado objetivo da educação, algo a ser conquistado, é também a principal via para levar os educandos a conhecer, imaginar, se interessar e produzir. A educação, ministrada informalmente pela comunidade ou formalmente nas instituições do Estado, quando tecida em meio a um universo comunicativo que é artístico, poético e retórico, torna-se mais efetiva porque torna o homem hábil para elaborar narrativas filosóficas, o que o dota de arbítrio e poder. O homem torna-se juiz e conquistador porque conversa, significa, cria, acredita e modifica. Seu poder não é como o das oligarquias, em que uns ordenam e outros - muitos outros - obedecem. Seu poder é o que permite alcançar boas condições para a vida em coletividade, em ambiente democrático, sem o que a pessoa fica reduzida à condição de escravo, figura que se define por não possuir o logos.

\section{Considerações finais}

Para Aristóteles, a polis é uma "comunidade de cidadãos” (A política III, 1, 1275a). Trata-se de um agrupamento que reúne indivíduos, 
em maior ou menor número, de maneira permanente, em um mesmo local, com a intenção de evitar a injustiça, promover a aliança militar, o intercâmbio, a subsistência, a proteção ou a prosperidade econômica (A política III, II, 1, 1261a20-30). Mas, além disso, a polis representa prioritariamente o local onde se promove a felicidade, a possibilidade de participar na virtude cívica, o envolvimento de todos nas deliberações sobre o bem comum (SANDEL, 2013).

A faculdade linguística dos homens propicia a consolidação de um modo de vida associativo que impulsiona o pensamento prudente e sábio, tornando-se fator sine qua non da instituição do homem como tal, e também da polis. A educação, prática linguística que viabiliza a comunicação, tem papel primordial no processo de produção humana, cultural e societária, tanto por permitir à pessoa realizar seu potencial e alcançar o bem individual, quanto por oferecer aos cidadãos a possibilidade de experienciar um modo de vida voltado para o bem da coletividade.

O mestre que educa artística e retoricamente, prezando pelo uso justo e convincente da palavra, conduz os educandos a obterem inúmeros proveitos na criação de bens; ele evidencia que o uso injusto e descuidado da linguagem pode ocasionar extremo dano para a experiência e a vida (Arte retórica, I, 1, 13). Considerando que as palavras ou formas comunicativas mais agradáveis são as que produzem mais conhecimentos, o professor, ou instrutor, estando atento para a qualidade poética da educação, usará expressões “elegantes” e "bem compostas”, que não começam nem terminam ao acaso, apresentando com "certa grandeza” e “clareza” o real, o possível, o que pode vir a ser, bem como o necessário e universal (Arte poética, VII, 8-12).

O conhecimento adquirido por intermédio da arte de educar pode conferir aos educandos poder e a força para debater, deliberar, convencer, criar e realizar, estimulando a liberdade, entendida como o agir com vontade própria baseado em deliberação consciente. Aristóteles explica que tanto a "coação externa” (ser empurrado, ameaçado etc.) quanto a "coação interna” (ser compelido por um estado de forte 
emoção, como a ira) contribuem para excluir ou diminuir a liberdade e também a força e o poder pessoais (ROHDEN, 2010, p. 159). Assim, quem pode agir com consciência, com propósito e ponderação, e por vontade própria torna-se livre, influente, respeitado e feliz. Esse resultado torna-se possível quando o contexto de existência envolve práticas educativas pautadas na comunicação, com vistas à produção de um homem dialógico, criativo, transformador, sempre ocupado com a realização do bem comum.

É o inverso do que se obtém quando a educação é pautada em Formas suprassensíveis, considerando que é o logos que arquiteta o mundo e os seres. O que a arte educativa com atributos poéticos e retóricos propõe é a alteração das condições de existência, consolidando a felicidade individual e concretizando uma polis ideal. Em última instância, seu objetivo é o fortalecimento do vínculo entre o indivíduo e a sociedade, uma vez que a busca pelo bem de todos tem valor para cada pessoa em particular, pois todos se reconhecem - percebem seus desejos e suas vozes - nas políticas que visam ao bem comum.

\section{Referências}

ANGIONI, Lucas. Introdução à teoria da predicação em Aristóteles. Campinas: UNICAMP, 2006.

. As noções aristotélicas de substância e essência. Campinas: UNICAMP, 2008.

ARISTÓTELES. De memoria. In: ARISTÓTELES. De sensu and De memoria. Tradução de G. R. T. Ross. Cambridge: Cambridge University, 1906.

- Arte poética. In: - Arte retórica e arte poética. Tradução de Antônio Pinto de Carvalho. São Paulo: Difusão Europeia do Livro, 1964a. 
Arte retórica. In: Arte retórica e arte poética. Tradução de Antônio Pinto de Carvalho. São Paulo: Difusão Europeia do Livro, 1964b.

. Analíticos posteriores. In: Órganon. Tradução de Edson Bini. Bauru: EDIPRO, 2005a.

. Categorias. In: . Órganon. Tradução de Edson Bini. Bauru: EDIPRO, 2005b.

. Tópicos. In: Órganon. Tradução de Edson Bini. Bauru: EDIPRO, 2005c.

. De anima. Tradução de Maria Cecília Gomes dos Reis. São Paulo: 34, 2006a.

$2006 b$.

Metafísica. Tradução de Edson Bini. São Paulo: EDIPRO, Ética a Nicômaco. Tradução de Edson Bini. São Paulo: EDIPRO, 2007.

. A política. Tradução de Nestor Silveira. São Paulo: Folha de São Paulo, 2010a.

. Partes dos animais. In: MESQUITA. António Pedro (Org.). Obras completas de Aristóteles. Tradução Maria de Fátima S. Silva. Lisboa: Centro de Filosofia da Universidade de Lisboa e Imprensa Nacional Casa da Moeda, 2010b.

Da interpretação. Tradução José Veríssimo Teixeira da Mata. São Paulo: Unesp, 2013.

AUROUX, Sylvain. A filosofia da linguagem. Tradução de José Horta Nunes. Campinas: UNICAMP, 1998.

BERTI, Enrico. Aristóteles no século XX. Traduçãode Dion Davi Macedo. São Paulo: Loyola, 1997. 
CASSIN, Bárbara. Aristóteles y el linguistic turn. In: CASSIN, Bárbara. Nuestros griegos y sus modernos. Estrategias contemporâneas de apropriación de la antigüedad. Traduçãode Irene Agoff. Argentina: Manantial Uruguay, 1994.

. Aristóteles e o lógos: contos da fenomenologia comum. Tradução de Luiz Paulo Rouanet. São Paulo: Loyola, 1999.

CASTRO, Susana. A teoria aristotélica da substância. Rio de Janeiro: Contraponto, 2008.

CHAMBLISS, Joseph James. Educational theory as theory of conduct: from Aristotle to Dewey. New York: State University of New York, 1987.

EIRE, A. López. Rhetoric and language. In: WORTHINGTON, Ian. A companion to Greek rhetoric. United Kingdom: Wiley-Blackwell, 2010.

GHIRALDELLI Jr., Paulo. Introdução à filosofia. Barueri: Manole, 2003.

MATA, José Veríssimo Teixeira. Comentários. In: ARISTÓTELES. Da interpretação. São Paulo: Unesp, 2013.

MEYER, Michel. Prefácio: Aristóteles ou a retórica das paixões. In: . Retórica das paixões. Tradução de Isis Borges B. da Fonseca. São Paulo: Martins Fontes, 2000.

MODRAK, Deborah K. W. Aristotle's theory of language and meaning. Cambridge: Cambridge University, 2001.

PERINE, Marcelo. Quatro lições sobre a ética de Aristóteles. São Paulo: Loyola, 2006.

ROHDEN, Luiz. O poder da linguagem: a arte retórica de Aristóteles. 2. ed. Porto Alegre: EdiPUCRS, 2010. 
REALE, Giovanni. História da filosofia antiga: das origens a Sócrates. Volume I. Tradução de Marcelo Perine. 4. ed. São Paulo: Loyola, 2002.

ROSS, G. R. T. Introduction and commentary. In: ARISTÓTELES. De sensu and De memoria. Tradução de G. R. T. Ross. Cambridge: Cambridge University, 1906.

SANDEL, Michael J. Justiça: o que é fazer a coisa certa. Tradução de Heloísa Matias e Maria Alice Máximo. 10. ed. Rio de Janeiro: Civilização Brasileira, 2013.

VOILQUIN, Jean; CAPELLE, Jean. Introdução. In: ARISTÓTELES. Arte retórica e arte poética. Tradução de Antônio Pinto de Carvalho. São Paulo: Difusão Europeia do Livro, 1964.

Data de registro: 31/10/2015

Data de aceite: 23/03/2016 